\title{
Structural Responses Data Measured in an Instrumented Flexible Pavement
}

\author{
Md Rashadul Islam ${ }^{1 *}$, Rafiqul A. Tarefder ${ }^{2}$ \\ 1. Colorado State University-Pueblo, 2200 Bonforte Blvd, Pueblo, CO 81001, USA \\ 2. Dept. of Civil Engineering, University of New Mexico, MSC 01 1070, 1 University of New Mexico, \\ Albuquerque, NM 87106, USA. \\ *E-mail:md.islam@csupueblo.edu (Corresponding author)
}

Received: 13 July 2019; Accepted: 16 August 2019; Available online: 20 November 2019

\begin{abstract}
This study presents and analyses the stress-strain responses data measured under real traffic conditions measured between Oct. 2012 to Oct. 2013 on an instrumented flexible pavement section on Interstate 40 (I-40) in the state of New Mexico, USA. Some weather variations data such as moisture and temperature variations at different depths of the pavement over the entire year are also discussed. The moduli of different layers determined using laboratory and field tests are also presented. It is expected that results of this study will be greatly useful to understand the behaviour of flexible pavement. The data presented in this study can be used to validate any constitutive or numerical model developed by readers.
\end{abstract}

Keywords: Flexible pavement; Instrumentation; Stress-strain responses; Temperature variations; Moisture variations; Wheel wander.

\section{Introduction}

Properties of Hot Mix Asphalt (HMA) largely depend on the climate conditions of the pavement site. The recently implemented Mechanistic-Empirical Pavement Design Guide (MEPDG), therefore, divides the year into several periods to encounter the seasonal effects in the structural response of flexible pavement. Predicted damages for each period are then, summed up to determine the yearly damage which is inverted to determine the design life. MEPDG determines the structural responses based on linear elastic analysis and hence, determine the possible damages. However, the actual field condition is not linear elastic.

Mateos et al. [1] measured the surface deflection and the horizontal strain under self-driven vehicle at a speed range of 20-30 km/h. The researchers correlated the response values with the HMA temperature. The decrease in stiffness with the passage of wheel loads was also presented. These data do not represent the behaviour of structural response with age of the pavement. In addition, these data were collected when the section had severely damaged in terms of surface cracks. Therefore, this data do not give the actual understanding of the new pavement.

Lin et al. [2] evaluated the seasonal effect of pavement on outdoor thermal environments in Taiwan. The research was mainly focussed on the determining the trend of surface temperature with air temperature in different seasons. It was concluded that surface temperature was most closely correlated with air temperature. The calculated heat output revealed that heat conduction strongly influenced total heat output which significantly affected the air temperature. The findings of the study are useful to understand the behaviour of the surface temperature of pavement. However, it did not conclude anything about temperature variations inside the pavement and corresponding structural responses due to vehicle load.

Schwartz and Carvalho [3] determined the seasonal variations of the stiffness of HMA using a parametric study in MEPDG and observed that the stiffness increased to more than 3.5 times for a $37.5 \mathrm{~mm}$ thick asphalt layer in the winter compared to the summer. The variations of the stiffness and the structural response with time were not studied in this study.

Tompkins et al. [4] presented the overview of the first ten years of the Minnesota Road Research project. The researchers discussed the qualitative observations of the test facility only. Orr [5] conducted a Falling Weight Deflectometer (FWD) test to measure in situ stiffness of the pavement material at various temperatures. The researcher discovered that the stiffness of the HMA in the winter increased to more than 4 times than that in the summer.

Figueroa [6] analysed the diurnal and the seasonal stiffness variations of HMA. The researcher reported that the HMA stiffness increased in winter (15512 MPa) dramatically from that in the summer (1724 MPa). Some diurnal effects were also considered in his study. It was reported that the stiffness was the maximum at 8:00 am 
and the minimum at 6:00 $\mathrm{pm}$. The above studies did not focus on the structural response of the pavement due to traffic and thermal loads.

Swett [7] attempted to characterize the seasonal variations of pavement layers' stiffness using the in situ measurement of pavement stress and strain. The researcher measured a noticeable larger asphalt strain than the predicted strain for increasing time of loading. The ratios of measured stresses and predicted stresses were between 2 and 2.5 for subbase and subgrade respectively. Therefore, no tangible conclusion was drawn in that study.

Al-Qadi et al. [8] described the thermal strain variation with temperature measured at the Virginia Smart Road and developed a numerical model to simulate the thermal fatigue cracking in asphalt pavement. In another study, Al-Qadi et al. [9] analysed the vertical stress and horizontal for different vehicle speeds, tire inflation pressures and temperatures using full scale field test and numerical analysis. The researchers successfully correlated the relationship of vertical stress with temperature and observed that the vertical varied exponentially with temperature. However, the variations of horizontal strain with temperature, moduli of different layers, moisture variations and vertical strain are still not discussed. All of these parameters vary with HMA mixtures, construction method and equipment used and the local climate.

Islam et al. [10] presented the diurnal variations of stress-strain under traffic load and the thermal strain at the bottom of the HMA. This study focused on the daily variations of these values with a single day data. The yearly variations along with other data (moisture, wheel wander, moduli of layers etc.) were not presented. Therefore, that study did not provide the full knowledge of the pavement.

The above discussion clarifies that there is no complete data available in the literature from where a reader can comprehend the entire phenomenon of pavement and use the data to develop or validate any constitutive and numerical model. The current study aims to provide and discuss a whole set of one-year data including stress, strain, temperature, moduli of different layers, moisture etc. under real field conditions collected from the instrumentation section located on Interstate 40 (I-40) at mile post 141 near the city of Albuquerque in the state of New Mexico, USA.

\section{Field instrumentation and data collection}

\subsection{Instrumented section}

The instrumented section has four layers. The top $263 \mathrm{~mm}$ layer is HMA followed by a $150 \mathrm{~mm}$ crushed stone base course. There is a subbase layer, called process place and compact (PPC) of $200 \mathrm{~mm}$ thickness and finally, underlain by the natural soil. The instrumentation profile view along with the installed sensors is shown Figure 1.

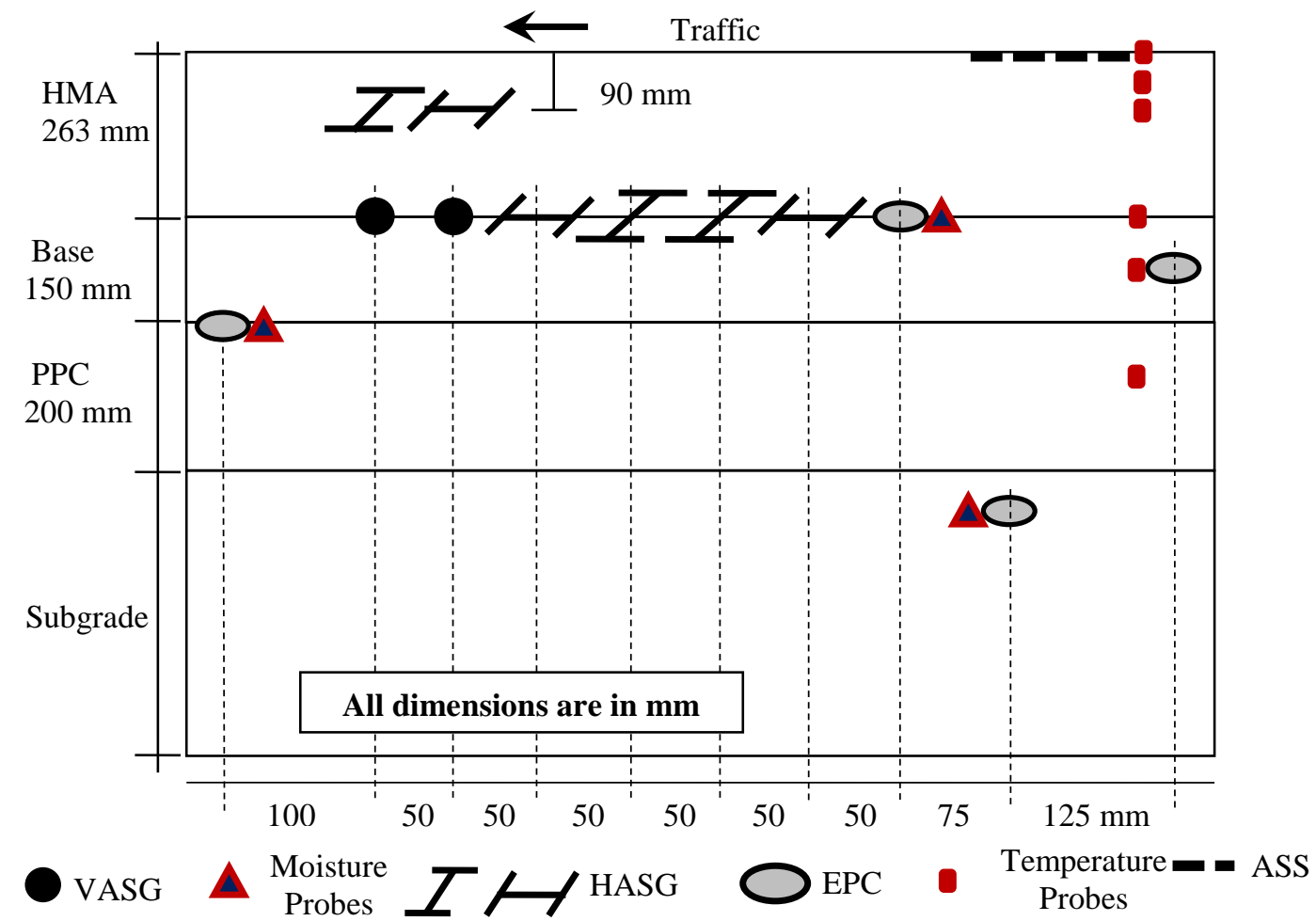

Figure 1. Longitudinal profile of the instrumented section. 
A total of 40 sensors are installed in the instrumented section to measure the vertical stress, horizontal strain, temperature variations, moisture variations, weather data, wheel wander and weight of the vehicle. The sensors are located at different elevations and positions of the section. The installation works were conducted in collaboration with National Center for Asphalt Technology (NCAT) at the Auburn University, Alabama, USA. The installation works is fully completed in October 2012.

\subsection{Sensors installation}

The horizontal strain at the bottom of the asphalt layer is a vital parameter in fatigue performance characterization. A total of 12 horizontal asphalt strain gages (HASGs), six oriented in longitudinal direction and six oriented transversely were installed at the bottom of the asphalt layer to measure the asphalt strain as shown in Figure 2(a). The array of gages was cantered in the outside wheel path with $600 \mathrm{~mm}$ offset from centre to capture the wheel wander of traffic.

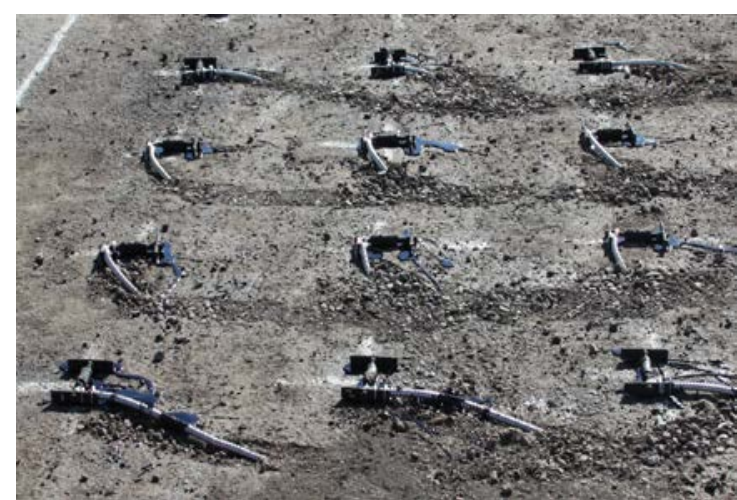

a) Layout of twelve of HASGs

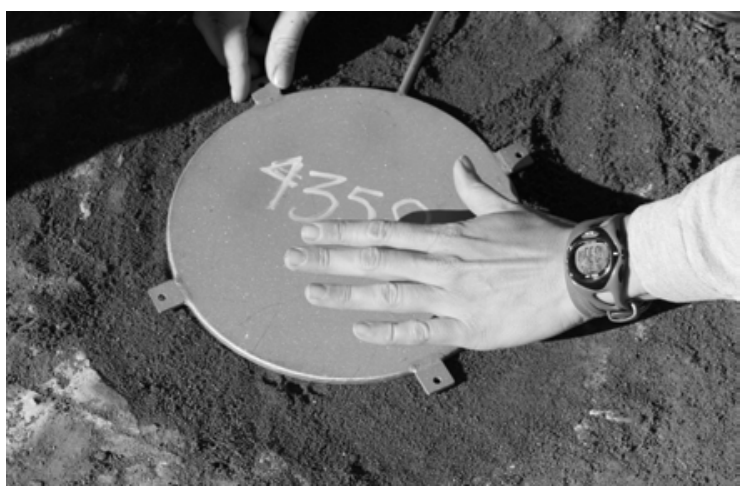

b) Installation of an earth pressure cell

Figure 2. Installation of the sensors.

Four earth pressure cells (EPCs) were installed at the top of the granular base layer, at the middle of the base, on the top of the PPC layer and on the top of the subgrade. A $300 \mathrm{~mm}$ square hole was prepared to accommodate the $225 \mathrm{~mm}$ diameter EPC as shown in Figure 2(b). The depth of the hole was approximately $63 \mathrm{~mm}$. A $75 \mathrm{~mm}$ wide by $75 \mathrm{~mm}$ deep trench was made with pick axes to accommodate the sensor's cable. The cable was inserted into $25 \mathrm{~mm}$ diameter corrugated aluminium pipe. This could protect the cable from the larger crushed stone. The EPCs were then placed such that each of the sensors had the exact elevation in the section. All the positions and elevations of the sensors were surveyed carefully and recorded for the analysis.

Three axle sensing strips (ASSs) were installed to measure the wheel wander and speed of traffic passing through the instrumentation section. The ASSs sensors were installed ahead of the HASGs array. Measuring wheel wander of traffic is essential as small deviation of traffic wheel from the sensors' centreline produces much different in stress-strain responses. Vehicle passing through the centreline of gage array are considered for the analysis. A weigh-in-motion (WIM) is also installed to measure the weight of the axles of traffic.

Six temperature probes were inserted at different depths (i.e. 0, 50, 90, 263, 340, $490 \mathrm{~mm}$ depths) of the pavement to measure the continuous temperature variations at these depths. The last two sensors measure the temperature at the middle of the base and the subbase. The installed weather station was used to measure the air temperature, solar radiation, rainfall and wind speed at the instrumentation site. The section also has six vertical asphalt strain gages (VASGs) at the bottom of HMA and three moisture probes at the layer interfaces. Reading of VASG is not presented in this study. Data from the sensors were recorded through a high-speed data acquisition system and processed by data analysis software called DaDisp.

\subsection{Hot mix asphalt}

Dense graded SuperPave (SP) mix, type SP-III was used in this section, which is widely used in New Mexico. This mix contains around 35\% plant screened recycled asphalt pavement (RAP) materials. Performance Grade (PG) binder PG 76-22 is $4.4 \%$ by the weight of mixture. The maximum aggregate size is $25 \mathrm{~mm}$ and the nominal maximum aggregate size is $19 \mathrm{~mm}$. About $5 \%$ of the materials pass through a No. 200 sieve $(0.075 \mathrm{~mm})$.

\section{Results and discussions}

\subsection{Temperature analysis}


Analysis of the pavement temperature is essential to correlate the moduli of each layer of the pavement with temperature. The pavement surface absorbs the heat from sunlight and transfers it to the underneath colder material. At night, this process is the opposite. The surface material draws up the heat from underneath the materials and transmits it to the air. Therefore, temperatures of the pavement materials are not the same all day long. This temperature variation makes changes in the mechanical properties of the pavement materials. The day of Feb. 5, 2013 is randomly chosen to describe the temperature variations in a day. Figure 3 shows the HMA temperature variations at different depths of surface layer on. It shows that surface temperature is the minimum in the morning and maximum in the afternoon. The temperature throughout the HMA section is almost same around 11:00 am and 10:00 pm. The average temperature (shown by solid line) is very close to the temperature at $50 \mathrm{~mm}$ depth up to 3:00 pm and decrease at faster rate. It can be observed that the mid depth (132 $\mathrm{mm}$ depth) temperature, though not interpolated in this figure, is not close to the average temperature. In addition, surface and shallow depth (up to $90 \mathrm{~mm}$ ) temperature are the minimum around 8:30 and 9:30 am and the maximum around 4:00 pm and 6:00 pm respectively. However, the temperatures at the bottom of HMA (263 mm depth) are the minimum and the maximum 10:30 am and 10:30 pm respectively.

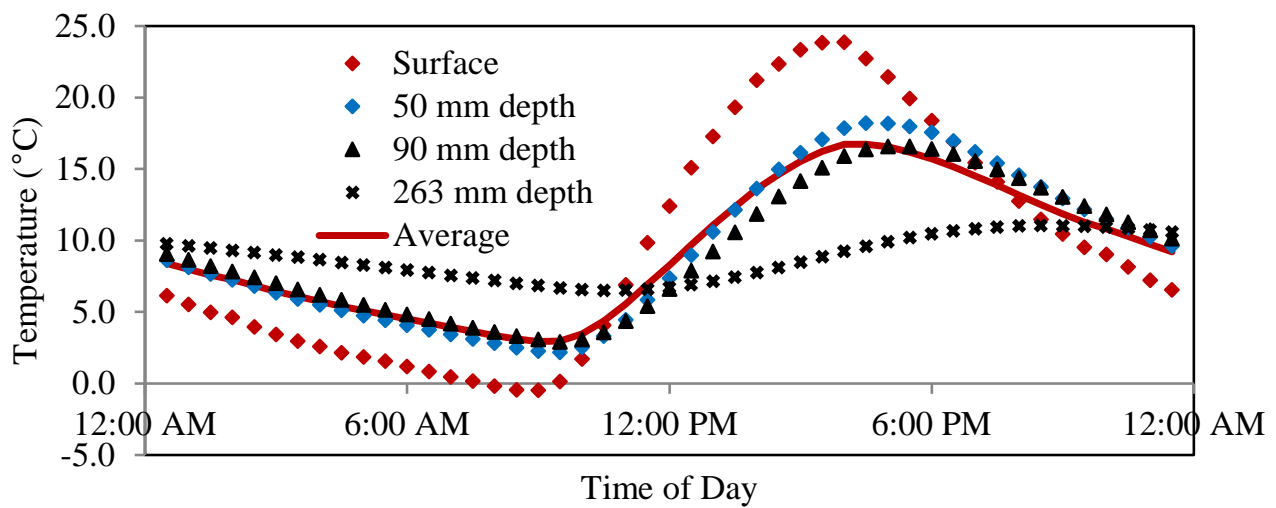

Figure 3. HMA Temperature variation over the day on Feb. 5, 2013.

Figure 4 shows the base (340 mm depth) and subbase (490 mm depth) temperatures on Feb 5, 2013 at the middepth of each layer. It shows that base and subbase temperatures vary between $7.5-9.9{ }^{\circ} \mathrm{C}$ and $8.2-8.6{ }^{\circ} \mathrm{C}$ respectively. Therefore, the day-night temperature differentials of base and subbase course are 2.4 and $0.4{ }^{\circ} \mathrm{C}$ respectively. It also can be observed that the subbase temperature is greater than base course from 7:00 am to 5:00 $\mathrm{pm}$. These temperature variations data are needed for correlating moduli of these layers with temperature. The subgrade temperature was not measured on this test section. It is assumed that the day-night temperature differential of subgrade is zero as the day-night temperature differential of subbase is only $0.4{ }^{\circ} \mathrm{C}$ and the average subbase temperature is considered the subgrade temperature.

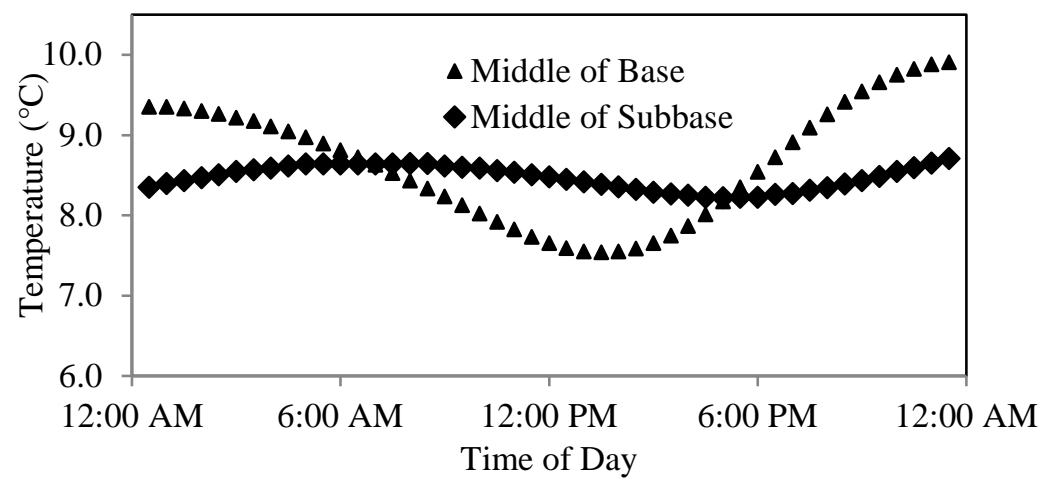

Figure 4. Base and Subbase temperature variations on Feb. 5, 2013.

The air and the average HMA temperatures from Oct. 2012 to Oct. 2013 are plotted in Figure 5. It shows that the average HMA temperature varies with the air temperature. However, the average HMA temperature is greater than the air temperature in most of the time of the year. That means the pavement material absorbs heat from the sunlight. 


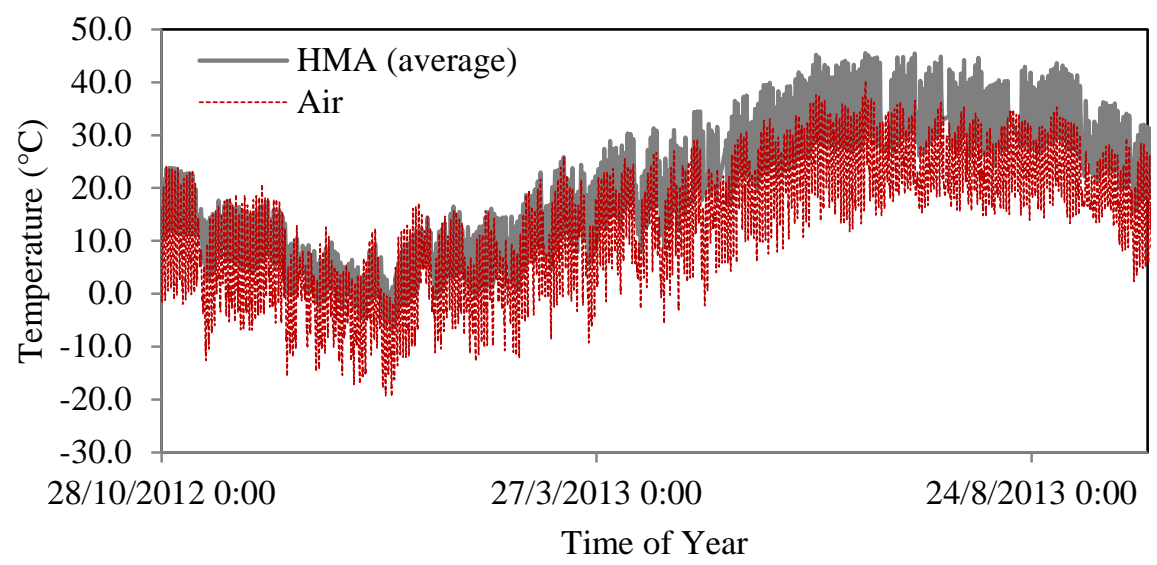

Figure 5. Variations of air and HMA temperatures from Oct. 2012 to Oct. 2013.

The variations of base and subbase temperatures with the average HMA temperature are plotted in Figure 6. It shows that the temperatures in base and subbase vary with the average HMA temperature. By visual inspection, it can be said that the average temperatures in base and subbase are almost equal to the average HMA temperature. From the above discussion, it can be concluded that the average temperatures in HMA, base and subbase are almost equal. The only difference is that the temperature fluctuation near the surface is relatively large compared to far away from the surface. The average yearly temperatures at the surface, in base and in subbase are $19.9{ }^{\circ} \mathrm{C}, 20^{\circ} \mathrm{C}$ and $20.1^{\circ} \mathrm{C}$ respectively. These values are very close to each other. The average HMA temperature during this time is measured to be $19.9^{\circ} \mathrm{C}$.

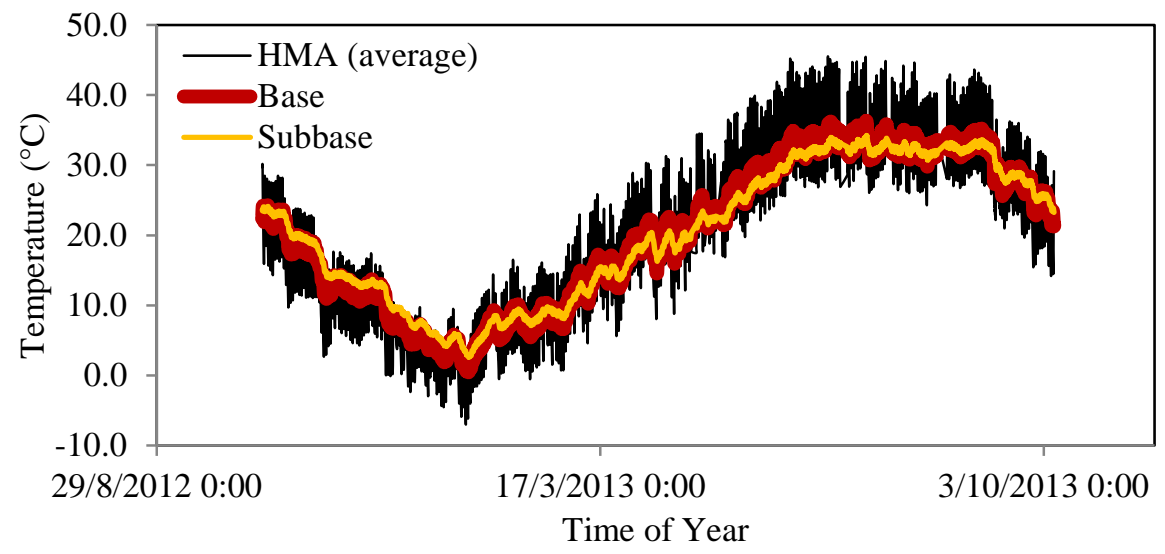

Figure 6. HMA, base and subbase temperatures from Oct. 2012 to Oct. 2013.

\subsection{Horizontal strains}

The horizontal strains at the bottom of HMA under real traffic and FWD loads are discussed in this section. The speed of the traffic is measured around $110 \mathrm{kmph}$. Horizontal strain due to the tandem axle of eighteen-wheel vehicle has been plotted in Figure 7 for different times on Feb 7, 2013. Ten vehicles have been considered each two-hour period and average values are plotted here. For instance, ten vehicles passing through centreline of installed strain gage between 9:00 am to 11:00 am are considered and reported the time as 10:00 am. The minimum value of $48 \mu \varepsilon$ and the maximum value of $82 \mu \varepsilon$ have been measured around 10:00 am and 10:00 pm respectively. The temperatures at the bottom of HMA (263 mm depth) are the minimum and the maximum 10:30 am and 10:30 pm respectively as shown in Figure 3. Therefore, conclusion can be drawn that horizontal strain is largely dependent of sensor level temperature.

Figure 8 presents the longitudinal and the transverse horizontal strains passing around 5:00 pm under dual wheel tandem axle load tire loads during Oct. 2012 to Oct. 2013. The temperature variation at the bottom of HMA during this time is also presented to correlate the strain value with temperature. The longitudinal and the transverse strains vary from 41 to $198 \mu \varepsilon$ and 45 to $233 \mu \varepsilon$, respectively, from the winter to the summer. It also shows that the tranverse strain is greater than the longitudinal strain in most of the cases. Garcia and Thompson [11] found the transverse strain $50 \%$ greater than the longitudinal strain. By visual inspection, it can be said that the horizontal strain varies proportionally with the temperature at the bottom of HMA. 


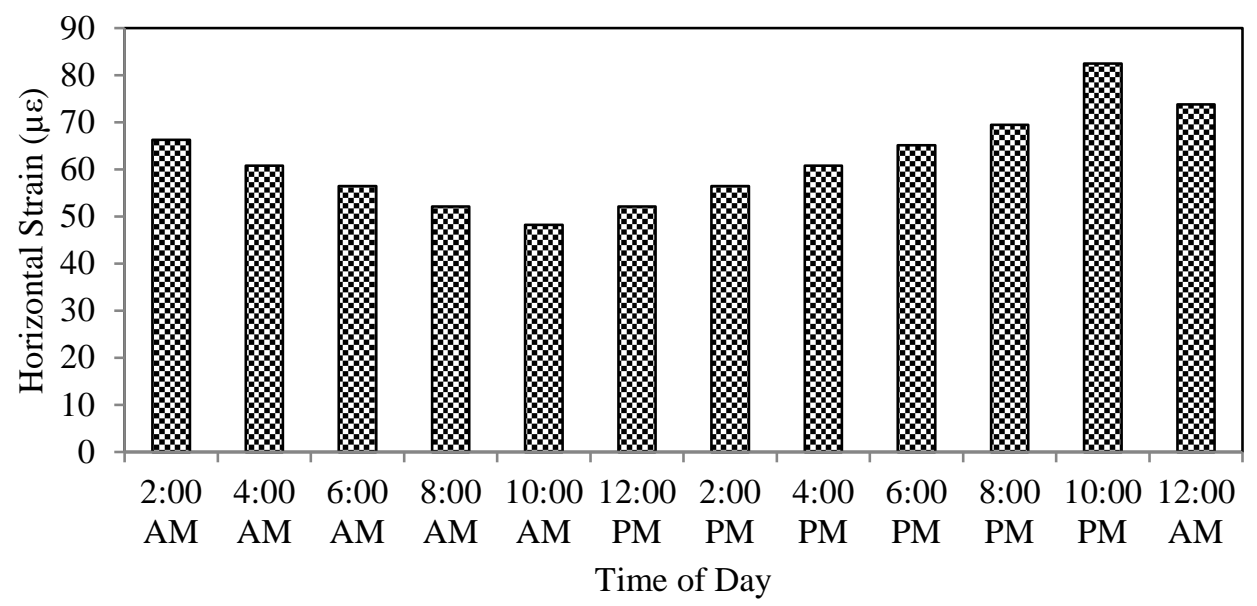

Figure 7. Variations of horizontal strain at the bottom of HMA due to dual wheel tandem axle load on Feb. 7, 2013.

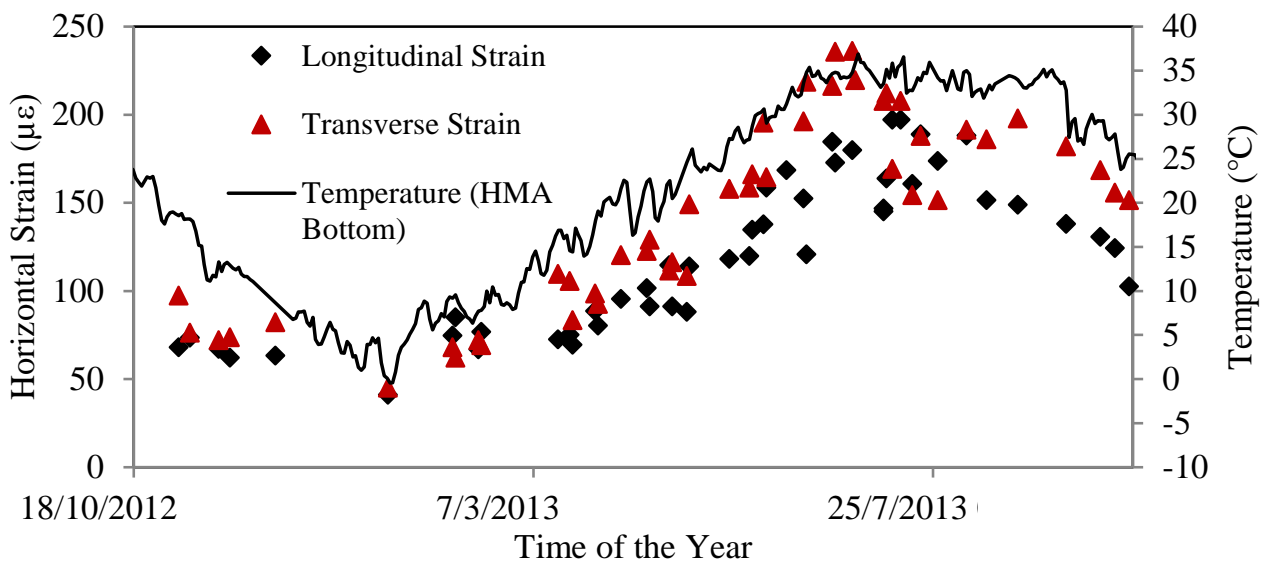

Figure 8. Variations of horizontal strain at the bottom of HMA around 5:00 pm under tandem axle dual wheel tire load.

The horizontal strain at the bottom of HMA under dual wheel tire load is plotted in Figure 9. The data has been recorded on Feb. 7, 2013 whole day and the variations of horizontal strain with surface temperature is plotted. Figure 9 shows that the strain value increases exponentially with increase in surface temperature. The horizontal strain increases from $50 \mu \varepsilon$ to $80 \mu \varepsilon$ for the temperature increase of around $3.5^{\circ} \mathrm{C}$ from $7.5^{\circ} \mathrm{C}$ to $11^{\circ} \mathrm{C}$.

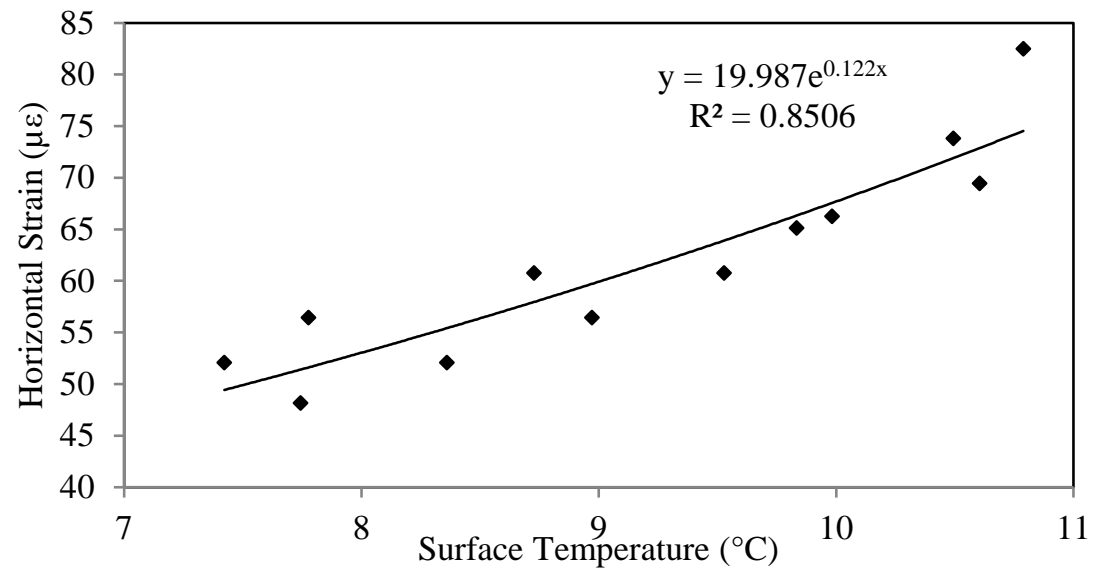

Figure 9. Variations of horizontal strain at the bottom of HMA on Feb. 7, 2013.

Figure 10 shows the horizontal strain variations at the bottom of HMA with the average HMA temperature under $40 \mathrm{kN}$ FWD load. The FWD test was conducted on different times of a day on a monthly basis starting from June 2012. The increase in horizontal strain with temperature for FWD load is low compared to traffic load. The 
horizontal strain increases from $50 \mu \varepsilon$ to $120 \mu \varepsilon$ for the temperature increase around $45^{\circ} \mathrm{C}$. Therefore, conclusions can be drawn that the structural response under moving traffic and FWD impact loads are way more different.

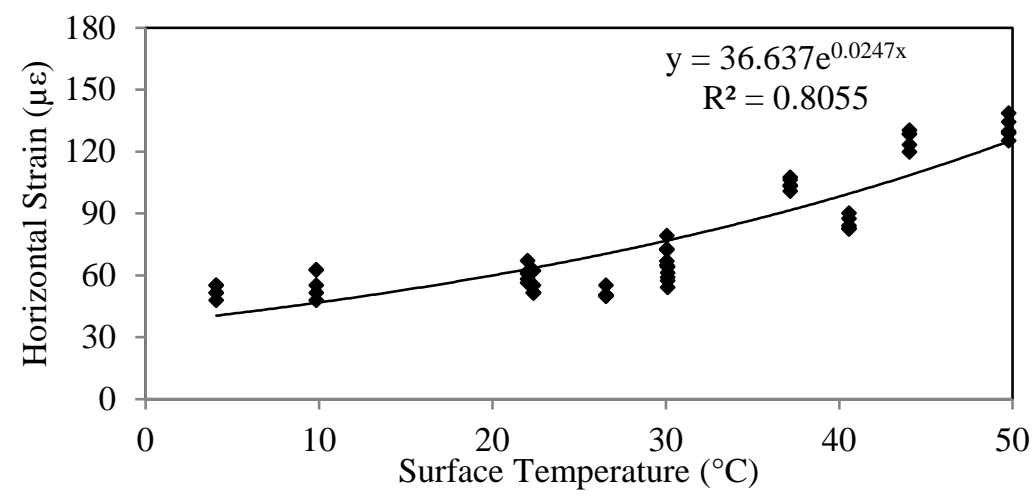

Figure 10. Variations of horizontal strain at the bottom of HMA under 40 kN FWD load.

\subsection{Vertical stress}

The vertical stresses are measured at four different depths of the pavement (i.e., on the top of the base, at midbase, on the top of the PPC and the Subgrade) due to both traffic and FWD loads; the corresponding depths are $263 \mathrm{~mm}, 338 \mathrm{~mm}, 413 \mathrm{~mm}$ and $513 \mathrm{~mm}$ respectively. The vertical stress decreases with increase in depth at any time of a day as shown in Figure 11. These stress distributions over the day for dual wheel tandem axle load at the four different depths are plotted in Figure 11. The stress magnitude decreases after midnight and reaches the minimum around 8:00 am in the morning. Then, it increases with the daylight and reaches the summit around 4:00 pm. The stress responses are more likely affected by surface temperature not the base, subbase not subgrade temperatures.

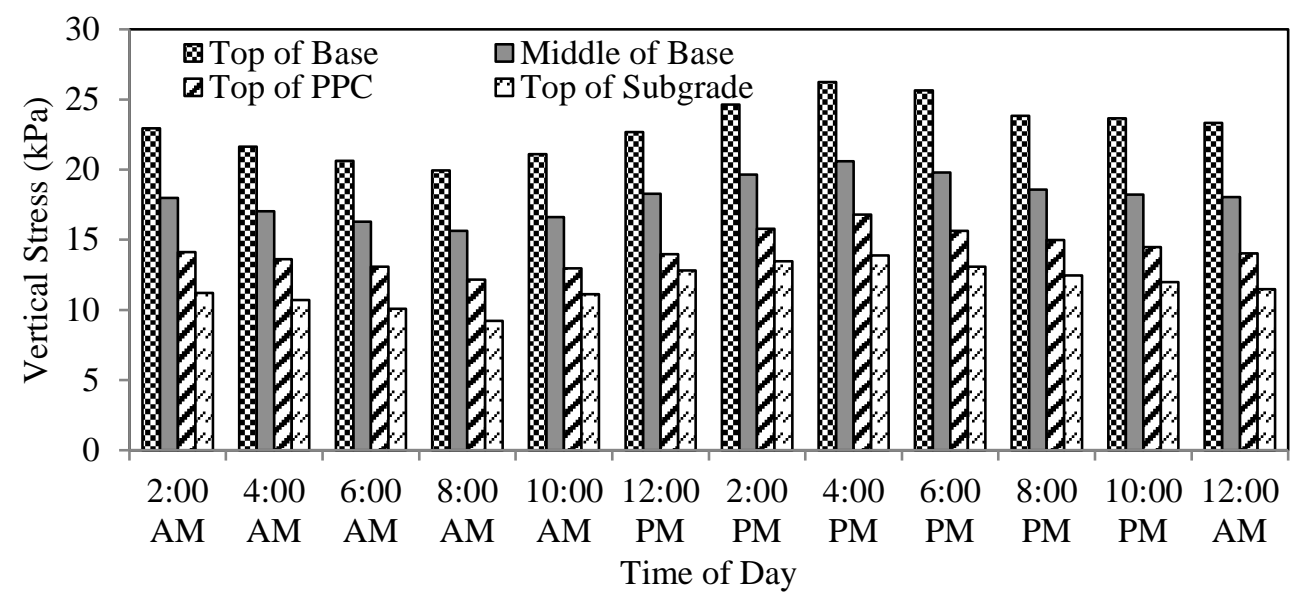

Figure 11. Vertical stress at different depths on February 7, 2013.

The minimum stress on the top of the base, at the middle of the base, on the top of the subbase and the Subgrade are 19.94, 15.63, 12.17 and $9.21 \mathrm{kPa}$ respectively. The maximum values at these depths are 26.24, 20.59, 16.78 and $13.88 \mathrm{kPa}$ respectively. Figure 11 also shows that the minimum and the maximum vertical stresses are obtained at 8:00 am and 4:00 pm respectively.

The stress variations under dual wheel tire load at different depths with the surface temperatures on Feb. 7, 2013 are plotted in Figure 12. The vertical stress increases with surface temperature. The best fitted trend lines are drawn in linear and exponential assumptions. Both of these assumptions produce the coefficient of determination $\left(\mathrm{R}^{2}\right)$ value close to unity (0.93-0.95). Therefore, conclusion can be drawn that linear assumption is sufficient enough to correlate the vertical stresss at the bottom of the HMA with surface temperature. However, the exponential relationship is more accurate than the linear assumption.

The variations of vertical stress due to $40 \mathrm{kN} \mathrm{FWD} \mathrm{load} \mathrm{at} \mathrm{different} \mathrm{surface} \mathrm{temperatures} \mathrm{are} \mathrm{presented} \mathrm{in} \mathrm{Figure}$ 13. It shows that the increase in vertical stress with increase in temperature from 4 to $23^{\circ} \mathrm{C}$ is gradual; after then the vertical stress increases sharply with surface temperature. 


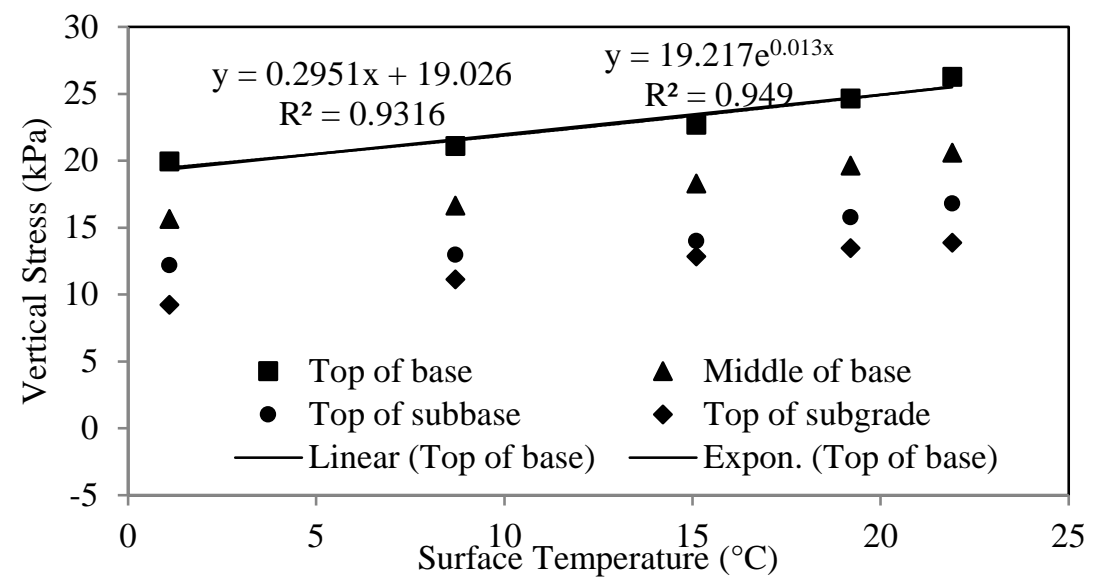

Figure 12. Variations of vertical stresses at different depths with surface temperature on Feb. 7, 2013.

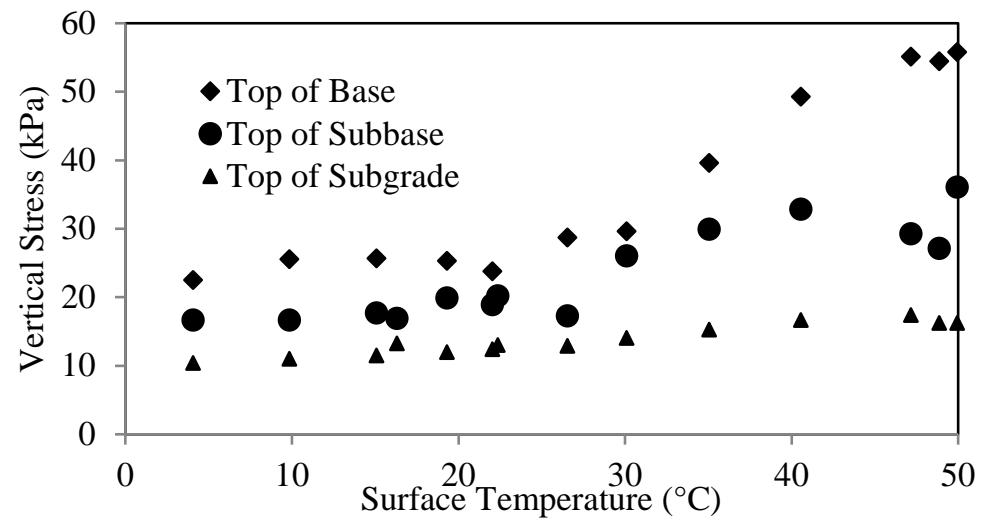

Figure 13. Variations of vertical stresses at different depths with surface temperature on due to $40 \mathrm{kN}$ FWD load.

Figure 14 present the vertical stresses at different depths along with the surface temperature of the pavement for single axle single tire load. The surface temperature varies from $9^{\circ} \mathrm{C}$ to $47^{\circ} \mathrm{C}$ during this period. It can be observed by visual inspection that the vertical stresses vary proportionally with surface temperature. The vertical stress on the top of the base ranges from $11 \mathrm{kPa}$ to $37 \mathrm{kPa}$ from winter to summer. This response is similar for other depths too.

Figure 15 present the vertical stresses at different depths along with the surface temperature of the pavement for tandem axle dual tire loads. The responses are similar to the responses of the single tire loads presented above. The vertical stress on the top of the base ranges from $22 \mathrm{kPa}$ to $68 \mathrm{kPa}$ from winter to summer.

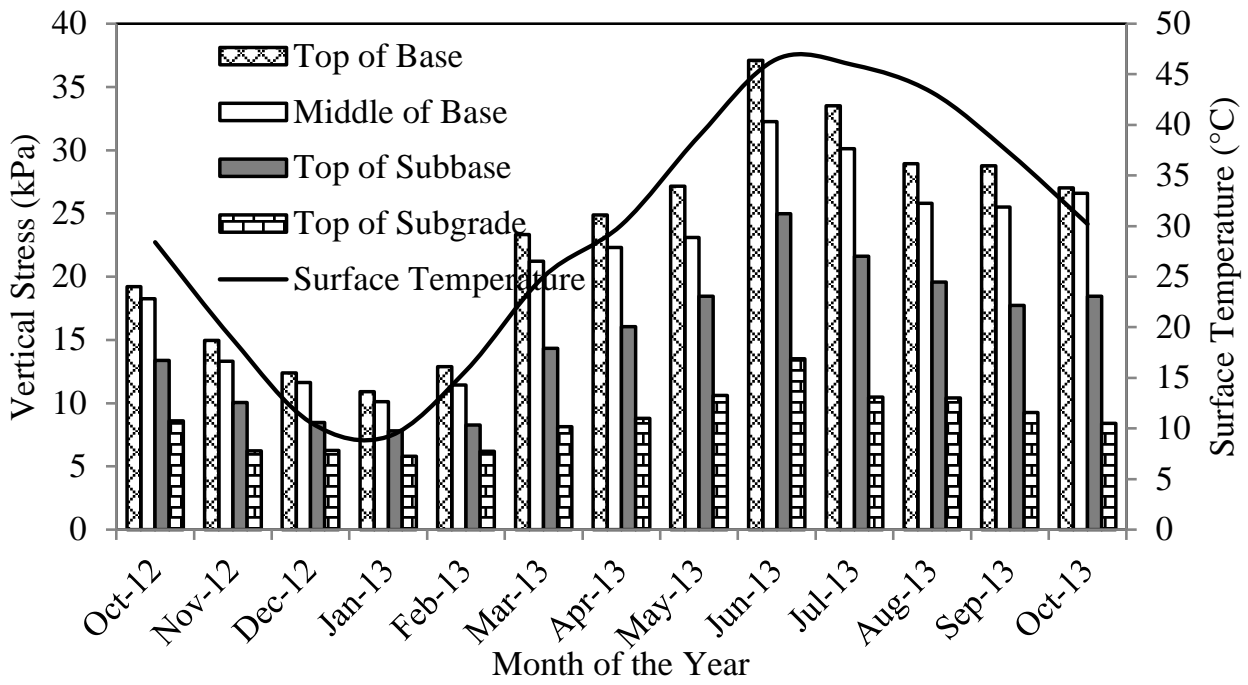

Figure 14. Vertical stress variations with surface temperature for single tire loads. 


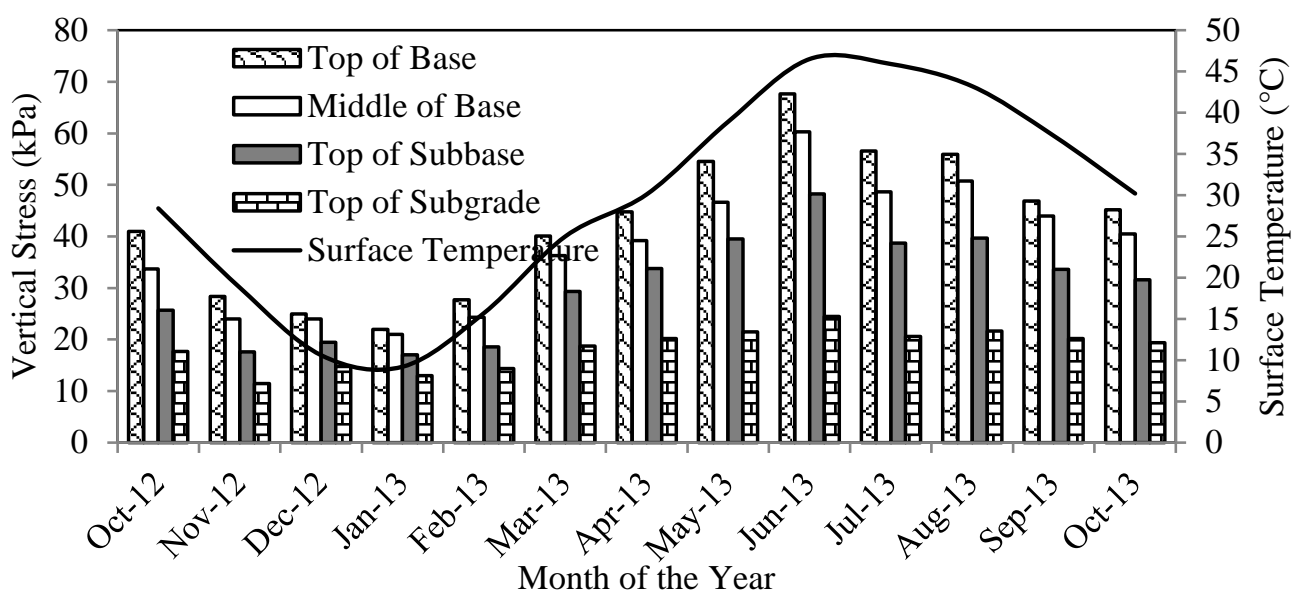

Figure 15. Vertical Stresses with surface temperature for dual tire loads.

\subsection{Moisture variations}

Moisture variations are monitored at three different depths (top of base, top of subbase and top of subgrade). The average volumetric moisture content from April 2012 to March 2013 is presented in Figure 16. It shows that the average volumetric moisture decreases with increase in depth. It makes sense that water infiltrates through the HMA and flow out laterally through base and subbase. The moisture content at any depth is the largest in July 2012. This is because the most of the rainfall occurs at this time at the test site as shown in Figure 17. The moisture variation on the top of base varies from $27 \%$ to $37 \%$ with an average value of $30 \%$. It varies from $20 \%$ to $30 \%$ on top of subbase with an average value of $23 \%$. In subgrade, this value ranges $10 \%$ to $14 \%$ with an average value of $13 \%$. The moisture variations seem greater than the usual value. The reason may be that the moisture probes were calibrated in a bucket of material compacted in the laboratory.

The relative humidity and rainfall variations at the test site are shown in Figure 17. The qualitative shape of the variations is logical in the sense that relative humidity increases after rainfall. An amount of $18.03 \mathrm{~mm}$ rainfall is observed on July 9, 2012. The yearly average rainfall of the test site is $0.02 \mathrm{~mm}$. The relative humidity of the test site varies from 2 to $94 \%$ with an average value of $31 \%$.

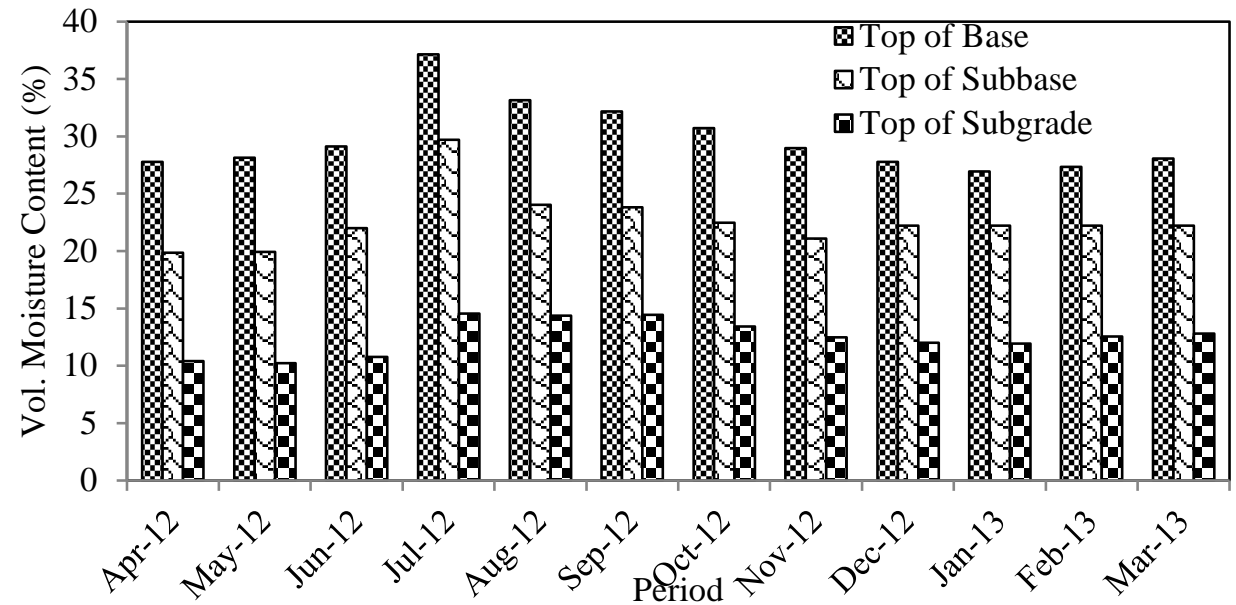

Figure 16. Average volumetric moisture content with time.

\subsection{Lateral wheel distribution}

Wheel wander or the lateral distribution of wheel loads is a natural phenomenon observed on all roadways. Accurate measurement of wheel wander is important since it dictates where the loads are placed and the frequency of loading at appoint of pavement. In addition, pavement damage is much greater if no wheel wander is considered $[12,13]$. In reality, wheel wander has a standard deviation ranging from $190 \mathrm{~mm}$ to $600 \mathrm{~mm}$ based on field studies on test track [12 - 14].

The above-mentioned studies have some limitations, yet these studies are still useful. For example, Blab and Litzka [15] considered only heavy vehicle on different road sections in Austria. The research was conducted based on the reading of a self-manufactured device called lateral displacement measurement (LDM). Detailed working principle and calibration information were not available. Buiter et al. [16] were particularly concerned with 
investigating how the wheel wander phenomenon relates to roads with a full-depth asphalt pavement with specific material properties. Stempihar et al. [14] measured the wheel wander based on painting on roads and recording the wheel path with camera. The procedure is not precise enough to measure the wheel wander accurately. Timm and Priest [13] considered the self-driven test vehicle only though the ASSs and laser sensors were used in this study. Based on the above discussion, it can be said that no accurate wheel wander value is still available. However, MEPDG developed in 2008, considers the centreline of wheel path to be $450 \mathrm{~mm}$ from outer edge of lane with a standard deviation (SD) value of $250 \mathrm{~mm}$ [17]

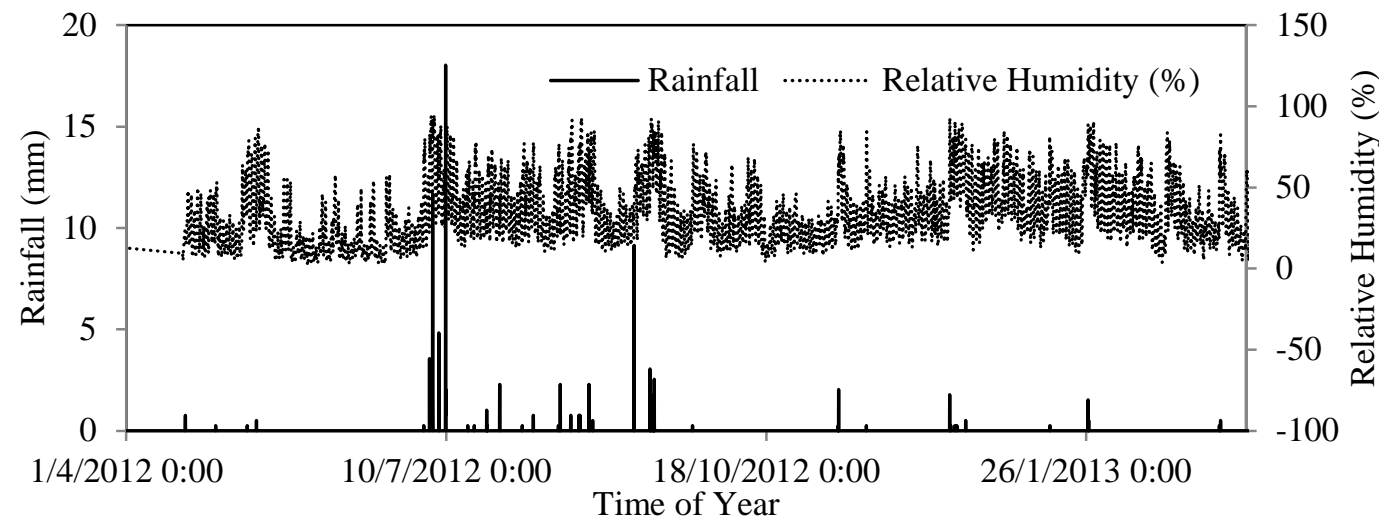

Figure 17. Relative humidity and rainfall variations with time.

The wheel wander of vehicle loads is measured from August 2012 to July 2013 between 4:00 pm to 6:00 pm daily for vehicle classes 4 to 13 . To determine the centreline of the wheel the reference point is assumed the edge of the white edge line of the pavement as shown in Figure 18. The distance between the edges of white mark and tire edge (L) is measured from the field data. For single wheel, the centreline is assumed to be $150 \mathrm{~mm}$ from the edge of the tire. For double wheel, the centreline is assumed to be $325 \mathrm{~mm}$ from the edge of the tire.

A total of 39200 axles have been considered. The wheel wander value is measured with reference to the right edge of the highway and ranges from $-111 \mathrm{~mm}$ to $1441 \mathrm{~mm}$; with an average value of $663 \mathrm{~mm}$ and median value of $469 \mathrm{~mm}$. The negative $111 \mathrm{~mm}$ means that the wheel passes $111 \mathrm{~mm}$ outside the edge line. The SD value of the wheel wander is $317 \mathrm{~mm}$, which differs by $67 \mathrm{~mm}$ from the MEPDG level 3 default value.

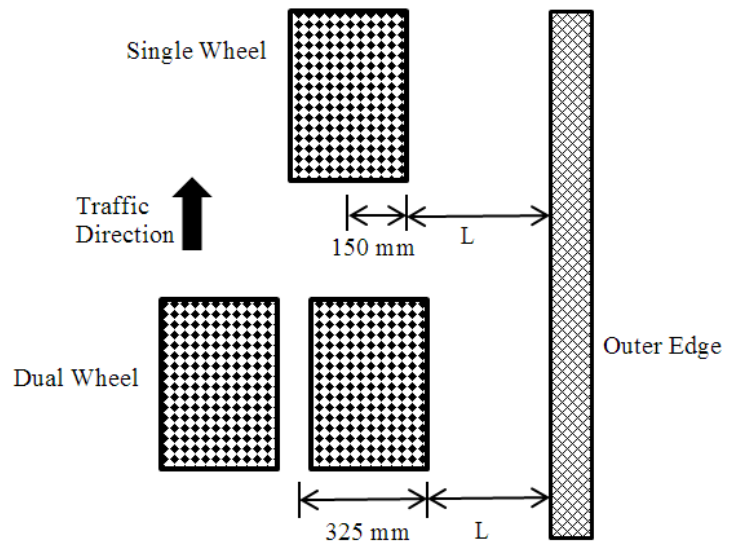

Figure 18. Procedure to determine the centreline of the wheel.

\subsection{Dynamic modulus}

To test, dynamic modulus of the HMA , two cylindrical samples of $150 \mathrm{~mm}$ diameter and $170 \mathrm{~mm}$ height were prepared following the AASHTO T 312-07 standard [18]. Then the sample was cut into $100 \mathrm{~mm}$ diameter and 150 mm height sample using a coring machine and laboratory saw. The bulk density and the theoretical maximum density were determined following the AASHTO T 166-07 [19] and the AASHTO T 209-05 [20] test standards respectively. The air voids of the samples range from $5.2 \%$ to $5.5 \%$ with an average value of $5.4 \%$. The $\left|E^{*}\right|$ tests were conducted using AASHTO T 342-11 [21].

The dynamic modulus $\left(\left|E^{*}\right|\right)(\mathrm{MPa})$ versus frequency $(\mathrm{Hz})$ mastercurves at $21.1^{\circ} \mathrm{C}$ were generated using AASHTO PP 62-09 [22] specification to compare the results. The following equation is used to fit the mastercurves: 


$$
\log |E *|=\delta+\frac{(\alpha)}{1+e^{\beta+\gamma}\left[\log f+a_{1}\left(T_{R}-T\right)+a_{2}\left(T_{R}-T\right)^{2}\right]}
$$

where $\alpha, \beta, \gamma, a_{1}$ and $a_{2}$ are the curve fitting parameters for the mastercurve, $f$ is the frequency of loading, $T_{R}$ is the reference temperature, and $T$ is any temperature other than the reference temperature. The reduced frequency $\left(f_{r}\right)$ is defined as:

$$
\log f_{r}=\log f+a_{1}\left(T_{r}-T\right)+a_{2}\left(T_{r}-T\right)^{2}
$$

The average values of the $\left|\mathrm{E}^{*}\right| \mathrm{s}$ of all the five samples have been used to determine the mastercurve of the sample. Figure 19 presents the developed mastercurves of both samples.

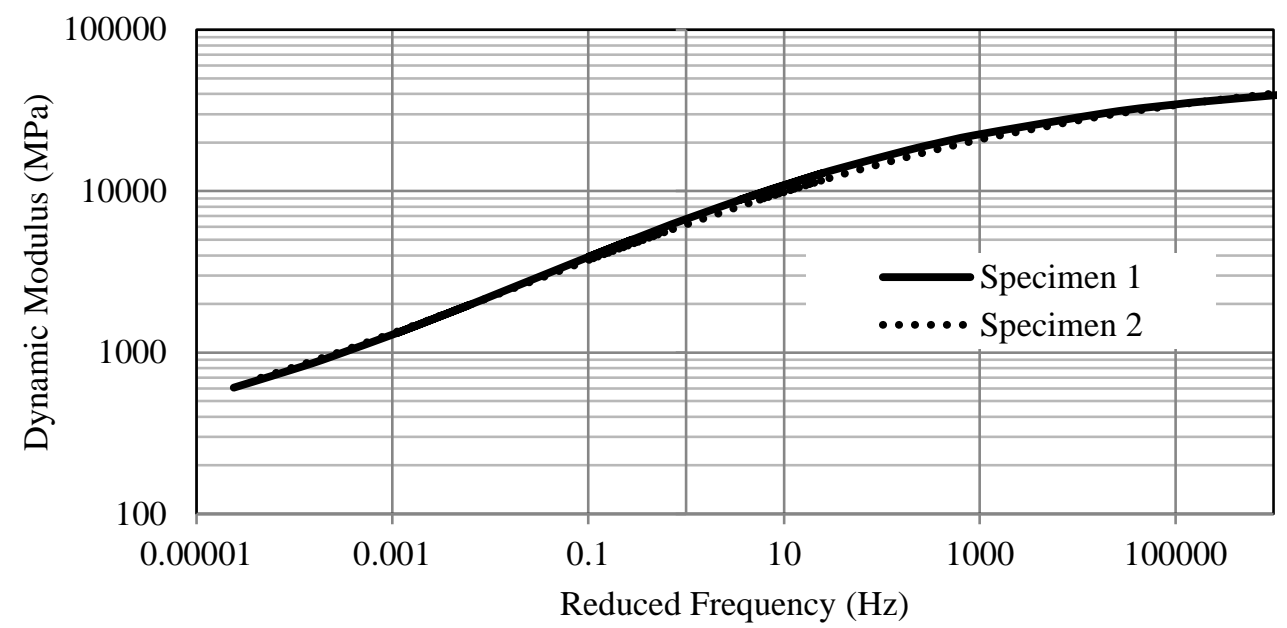

Figure 19. The mastercurve of the dynamic modulus

The $\left|E^{*}\right|$ at different temperatures and frequencies are plotted in Figure 20. The $\left|E^{*}\right|$ varies $2128 \mathrm{MPa}$ to 44970 $\mathrm{MPa}$ for the temperature variations from $54^{\circ} \mathrm{C}$ to $-10^{\circ} \mathrm{C}$ at $25 \mathrm{~Hz}$ of loading. At $0.1 \mathrm{~Hz}$, this value ranges from $602 \mathrm{MPa}$ to $27982 \mathrm{MPa}$ at this temperature range.

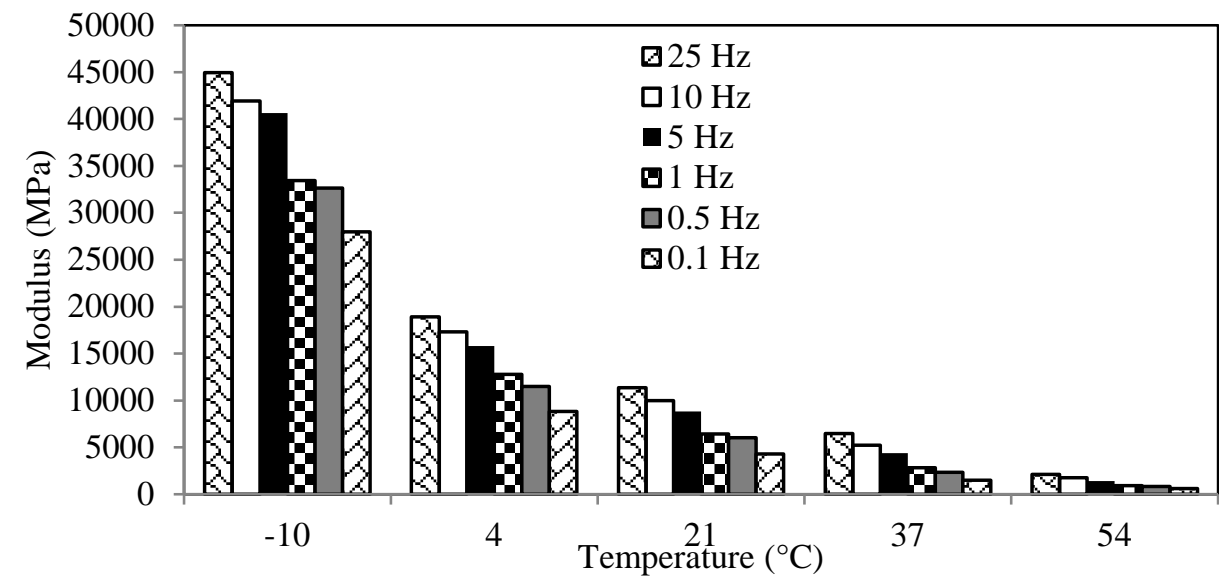

Figure 20. The dynamic moduli with test temperature at various frequencies (redrawn from Islam et al. [23]).

\subsection{Moduli of different layers}

The moduli of different layers are obtained from one of the author's previous study [10]. The moduli were obtained by conducting FWD test. The test was conducted on the final layer of the pavement section before the pavement was opened for traffic in the first week of June 2012. An impulse load is applied on the surface by dropping a weight and transmitted to the pavement surface through a circular steel plate. The pavement surface deflects vertically forming a deflection basin. Surface deflections are measured through geophones locating at different distances from loading point. The backcalculation software, ELMOD is used to backcalculate the stiffness of different layers. 
The average moduli of HMA, base, subbase and subgrade are 1720, 205, 172 and 103 MPa respectively determined using FWD test. The resilient moduli determined using AASHTO T307-99 [24] are obtained from previous of studies of Islam et al. [10]. The resilient moduli of base and subbase are $637 \mathrm{MPa}$ and $710 \mathrm{MPa}$ at 50 $\mathrm{kPa}$ deviatoric stress respectively. These values are obtained using internal linear variable displacement transducers (LVDTs). The values are close to the FWD backcalculated values if external LVDTs are used.

\section{Conclusions}

This study provides a complete set of annual field data collected from the instrumentation section on I-40. The data will be useful to understand the pavement behaviour and to develop any numerical and constitutive model. Specifically, the following conclusions can be made from this study:

1) The vertical stress at any depth of the pavement varies linearly in short surface temperature range.

2) The horizontal strain at the bottom of HMA varies with the temperature at this depth.

3) The variation of horizontal strain with temperature is less sensitive for FWD load compared to moving traffic load.

4) The moisture content decreases with depth of the pavement and influenced by the rainfall.

\section{Acknowledgements}

This research is funded by the New Mexico Department of Transportation (NMDOT), Grant No. NM11MSC03. The authors would like to appreciate the research funding provided by the New Mexico Department of Transportation (NMDOT). The help of Dr. Timm from NCAT, Auburn University in installing the temperature probes is also acknowledged.

\section{References}

[1] Mateos A, Ayuso J, Cadavid B. Evaluation of the structural response of cracked pavements at CEDEX test track. Transportation Research Board Annual Meeting, Paper No. 13-4458. Washington DC. 2013.

[2] Lin TP, Ho YF, Huang YS. Seasonal effect of pavement on outdoor thermal environments in subtropical Taiwan. Building and Environment. 2007;42(12):4124-4131.

[3] Schwartz C, Carvalho R. Evaluation of mechanistic-empirical design procedure. Final Report. MDSHA Project No. SP0077B41. Maryland. 2007.

[4] Tompkins DM, Khazanovich L, Johnson DM. Overview of the first ten years of the Minnesota road research project. Journal of Transportation Engineering. 2007;133(11):599-609.

[5] Orr DP. Seasonal variations of in situ materials properties in New York State: FWD testing and data analysis to define seasonal variability. CLRP Report No. 05-01. New York State Department of Transportation. 2005.

[6] Figueroa JL. Monitoring and analysis of data obtained from moisture temperature recording stations. Final Report, Job No. 14589(0). Ohio Department of Transportation, OH. 2001.

[7] Swett LJ. Seasonal variations of pavement layer moduli determined using in situ measurement of pavement stress and strain. M.S. Thesis. Department of Civil and Environmental Engineering, University of MaineMain. 2007.

[8] Al-Qadi IL, Hassan MM, Elseifi MA. Field and theoretical evaluation of thermal fatigue cracking in flexible pavements. Transportation Research Record. 2005;1919(1):87-95.

[9] Al-Qadi IL, Loulizi A, Elseifi M, Lahouar S. The virginia smart road: The impact of pavement instrumentation on understanding pavement performance. Journal of the Association of Asphalt Paving Technologists. 2004;73(3):427-465.

[10] Islam MR, Rahman MT, Ahmed MU, Tarefder RA. Evaluating moduli of base and subbase layers in flexible pavement. In: Proceedings of the ASCE Texas Section Spring Conference and Centennial Celebration. March 19-23, 2013 at Corpus Christi, Texas. Paper ID SP-5, p. 1-14.

[11] Garcia G, Thompson MR. Strain and pulse duration considerations for extended-life hot-mix asphalt pavement design. Transportation Research Record. 2008;2087(1):3-11.

[12] Epps JA, Hand A, Seeds S, Schulz T, Alavi S, Ashmore C, Monismith C, Deacon J, Harvey J, Leahy R. Recommended performance-related specification for hot-mix asphalt construction: Results of the Westrack project. NCHRP Report 455. Transportation Research Board, National Research Council. 2002.

[13] Timm DH, Priest A. Wheel wander at the NCAT test track. NCAT Report 05-02. Alabama Department of Transportation, Alabama, USA. 2005.

[14] Stempihar JJ, Williams RC, Drummer TD. Quantifying the lateral displacement of trucks for use in pavement design. Transportation Research Board Preprint. Washington, D.C. 2005. 
[15] Blab R, Litzka J. Measurements of the lateral distribution of heavy vehicles and its effects on the design of road pavements. In: Proceedings of the International Symposium on Heavy Vehicle Weights and Dimensions, Road Transport Technology. University of Michigan; 1995. p. 389-395.

[16] Buiter R, Cortenraad W, Van A, Van H. Effects of Transverse distribution of heavy vehicles on thickness design of full-depth asphalt pavements. Transportation Research Record No. 1227. Transportation Research Board, Washington, D.C.;1989. p.66 - 74.

[17] AASHTO. Mechanistic-empirical pavement design guide. A manual of practice, Interim Edition. American Association of State Highway and Transportation Officials, Washington, D. C. July 2008.

[18] AASHTO T 312-07. Preparing and determining the density of hot-mix asphalt (HMA) specimens by means of the superpave gyratory compactor. Standard specifications for transportation materials and methods of sampling and testing, 27 $7^{\text {th }}$ Edition. American Association of State Highway and Transportation Officials, Washington, D.C. 2007.

[19] AASHTO T 166-07. Bulk specific gravity of compacted hot mix asphalt using saturated surface-dry specimens. Standard specifications for transportation materials and methods of sampling and testing, $27^{\text {th }}$ Edition. American Association of State Highway and Transportation Officials, Washington, D.C. 2007.

[20] AASHTO T 209-05. Theoretical maximum specific gravity and density of hot mix paving mixtures. Standard specifications for transportation materials and methods of sampling and testing, $27^{\text {th }}$ Edition. American Association of State Highway and Transportation Officials, Washington, D.C. 2007.

[21] AASHTO T 342-11. Determining dynamic modulus of hot-mix asphalt concrete mixtures. Standard specifications for transportation materials and methods of sampling and testing. American Association of State Highway and Transportation Officials, Washington, D.C. 2011.

[22] AASHTO PP 62-09. Standard practice for developing dynamic modulus master curves for hot mix asphalt (HMA). Standard specifications for transportation materials and methods of sampling and testing. American Association of State Highway and Transportation Officials, Washington, D.C. 2009.

[23] Islam MR, Mannan UA, Rahman A, Tarefder RA. Effects of recycled asphalt pavement on mix and binder properties and performance in the laboratory. TRB Annual Meeting 2014, Paper No. 14-4748. Washington, D.C. 2014.

[24] AASHTO T 307-99. Determining the resilient modulus of soils and aggregate materials. Standard specifications for transportation materials and methods of sampling and testing. American Association of State Highway and Transportation Officials. Washington, D.C. 2007.

(c) 2019 by the author(s). This work is licensed under a Creative Commons Attribution 4.0 International License (http://creativecommons.org/licenses/by/4.0/). Authors retain copyright of their work, with first publication rights granted to Tech Reviews Ltd. 